Proceedings of the 2011 Winter Simulation Conference

S. Jain, R.R. Creasey, J. Himmelspach, K.P. White, and M. Fu, eds.

\title{
FLEXIBLE MODEL FOR ANALYZING PRODUCTION SYSTEMS WITH DISCRETE EVENT SIMULATION
}

\author{
Alexander Hübl \\ Klaus Altendorfer \\ Herbert Jodlbauer \\ Upper Austria University of Applied Sciences \\ Production and Operations Management \\ Wehrgrabengasse 1-3 \\ 4400, Steyr, AUSTRIA
}

\author{
Margaretha Gansterer \\ Richard F. Hartl \\ University of Vienna \\ Department of Business Administration \\ Brünner Strasse 72 \\ 1210, Vienna, AUSTRIA
}

\begin{abstract}
This paper presents the structure of a flexible discrete event simulation model for analyzing production systems. Based on BOM and routing information a simulation model is generated to analyze a shop floor structure. Different modules are used for generating customer orders and production orders and handling the material flow until the customer is satisfied. The basic idea is that the modules are not connected directly together but the material flow is routed according the information defined in BOM and routing. The model can apply stochastic behavior for processing times, set up times, purchasing lead time, customer required lead time, customer required amount and segmentation from product group to final product. Conwip and MRPII including MPS are implemented as production planning and control methods. The simulation model can be used for analyzing complex production system structures to evaluate the logistical performance.
\end{abstract}

\section{INTRODUCTION}

The market situation for manufacturing companies is often difficult and unpredictable due to product complexity and changing demand, even though most markets have overcome the financial crisis. Companies are committed to improving their overall logistics performance. Fawcett and Cooper (1998) identified that firms are trying to manage the tradeoff between cost and customer service. To influence logistical performance decisions for the right production planning and control (PPC) strategy, parameterization of selected PPC, and capacity investment have to be taken.

Analytic models like Jodlbauer and Altendorfer (2010) and Koh and Bulfin (2004) discuss such decisions to influence logistical performance. Since such models lack practical feasibility, discrete event simulation has become more popular in the last decades (Huang, Wang, and Ip 1998; Kutanoglu and Sabuncuoglu 1999; Abdul-Kader and Gharbi 2002; Jodlbauer and Huber 2008).

As discussed by Thompson (1994), simulation models have traditionally been used for planning and design but neglect the implementation and operation phase. After the planning and design phase, models are seldom used and models for these phases are therefore often called "throw away models."

Moreover, traditional simulation models, where the data and logic is embedded in the simulation model, are created for a certain case (Randell and Bolmsjo 2001). Analyzing alternatives again requires personnel and time investment to adapt the simulation model, because the code of the model has to be adjusted.

For a discrete event simulation study the most time consuming phase is the input data collection and model development (Trybula 1994, Perera and Liyanage 2000, Randell and Bolmsjo 2001). 
Many authors have developed integrated solutions for modeling enterprises (Heim 1997; Srinivasan and Jayaraman 1997; Whitman, Huff, and Presley 1997; Delen, Benjamin, and Erraguntla 1998). These models can be used as basis for the simulation model in terms of aggregation of materials, resources and time. This leads to the development of a flexible discrete event simulation model structure in an object oriented environment (Borenstein 2000; Anglani et al. 2002).

Taking the above arguments into account, a flexible discrete event model implemented in Anylogic 6.5. is developed, where the input data for the simulation model is defined in a database. Based on this information the simulation model is created. The advantage is to generate simulation models based on the input data for any kind of production system structures, whereby the following planning levels according to Hax and Meal (1975) and Meal (1984) are implemented:

- Long term: capacity investment decisions like number of machines

- Medium term: like shift model, overtime, BOM (bill of material) structure, PPC Method like MRPII (manufacturing resource planning) or Conwip (constant work in process), production system structure like flow shop or job shop

- Short term: operational level such as dispatching rules like FIFO (first in first out) or EDD (earliest due date)

\section{MODEL}

To enable the flexible simulation structure, configuration tables for BOM, routing, capacities and customer behavior are introduced in the database. These tables are transferred in the beginning of the simulation through the simulation environment, whereby in the following initialization process the simulation model is created based on this information.

$\mathrm{BOM}$ and routing contain the information of parent and child items and where the production process is executed with its parameters like processing times, set up times and planned lead time. In the capacity table the number of machine groups and its machines is defined. Finally the customer behavior table defines the inter arrival time between customer orders of certain product groups and the amount of a certain order.

The following assumptions are introduced:

- $\quad$ one PPC method for all materials and low level codes (LLC)

- no amount distribution for purchased items; only replenishment lead time is distributed

- no visualization for sake of short model runtimes

- processing times for all child items of a parent item are equal

- purchasing, processing and set up times are exponentially distributed

- compound Poisson distributed demand with Lognormal order amount

- production lot size is transport lot size to the production step; transport lot size after the production step is one piece

- exponentially distributed mean time between failure (MTBF) and mean time to repair (MTTR)

- same dispatching rule for all machines

Figure 1 shows the simulation model, where the material and information flow is illustrated. Basically the simulation model consists of 6 modules. The "Order Generation" creates the customer orders, which are used for the customer group to pull the finished products from the FGI. The customer orders are also the input for production planning. The production planning creates production orders based on the MRPII or Conwip method. The production orders activate the purchase process in the module Procurement or they are used for releasing the material in the Production Control module. Beside material provision, the module Production Control also represents the inventory where raw material, purchased items, semifinished items and end items are stored. After releasing the material according to the production order, material and production order are sent to the specified machine group. After the production process is finished the material is again put into inventory in the module Production Control. 


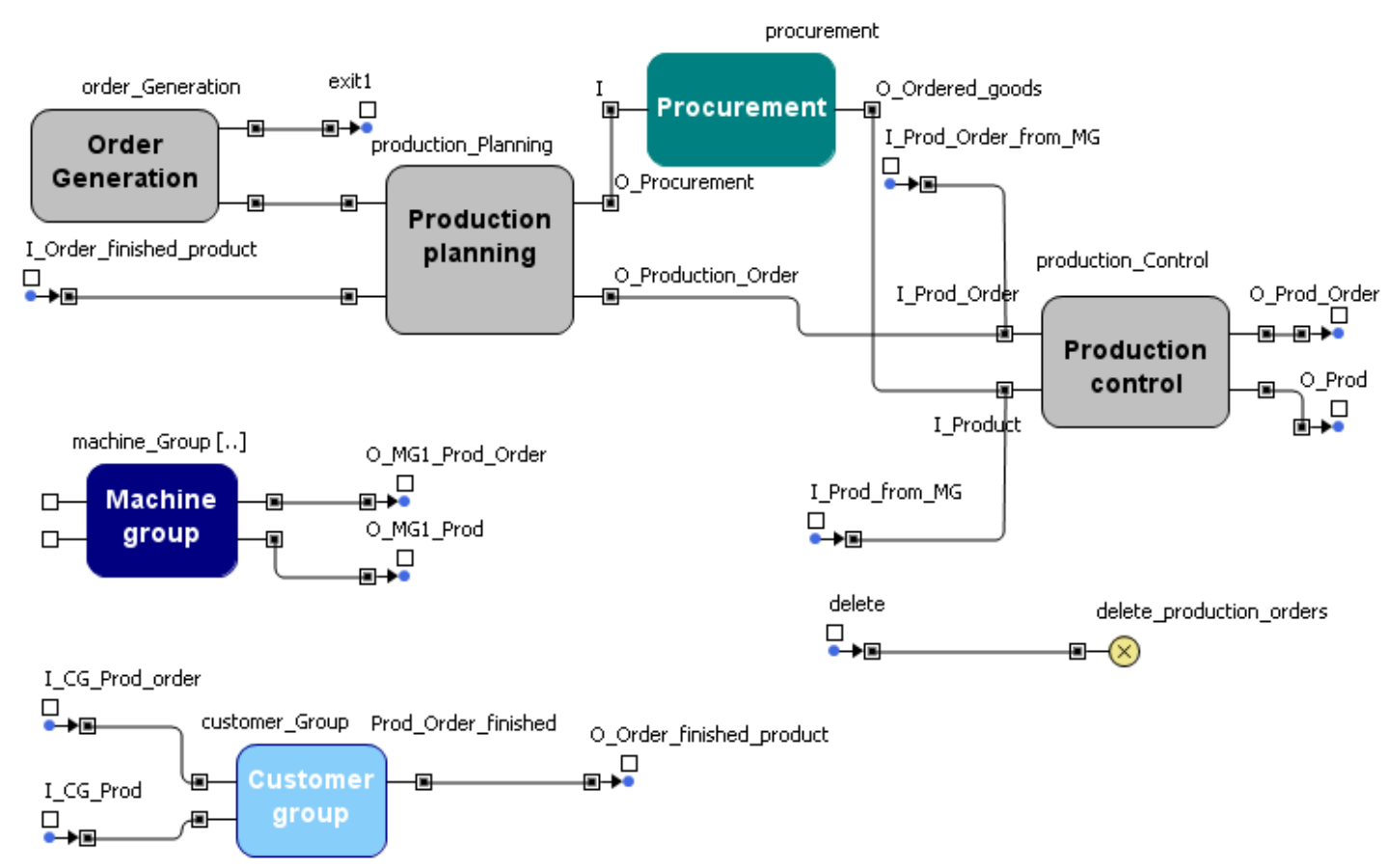

Figure 1: Simulation model

\subsection{Input Data}

The most important table in the database corresponds to routing and BOM. A combined table called WS Master for both routing and BOM is developed as depicted in Figure 2. The WS Master consists of three important attributes:

- Parent item: a parent item consist of one or more child items

- Child item: item which is necessary to build a parent item; if a parent item consists of more than one child item then this row exists several times whereby the child items differs

- Machine group: indicates the machine where the parent item is produced

Two descriptive examples for explaining the WS Master are created. For case 1 shown in Figure 2a a serial BOM structure with one end item whereby two production steps are necessary for forming the end product 3201 out of a raw material 1301 is chosen. These two production steps are performed on the machine groups 1 and 2. This results in a WS master with three rows. The first row indicates that the parent item 3201 consists of the child item 2101 and the production step is performed on machine group 2. Due to the fact that a serial BOM structure exists the second row explains that material 2101 needs material 1301 and the step is produced on machine group 1. Finally, the last row indicates that 1301 is a raw material because zero is assigned to the attribute child item.

Case 2 in Figure $2 \mathrm{~b}$ shows a convergent and divergent structure of the BOM, whereby two end items 3201 and 3202 exist. Material 3202 consists of two child items 2101 and 2302. Such convergent BOM list structures are applied in the WS Master with two entries whereby the same parent item is listed in both entries. Thus, the child item is different in each entry. A divergent BOM structure exists for material 2101 because the end item 3201 or 3202 can result after the last production step. The implications of this structure for the WS Master are that for both end items 3201 and 3202 an entry with the same child item exists (see row 1 and row 2). 2302 is a purchased part which is indicated by a zero under the attribute child item.

Of course more attributes exist for the WS Master to configure the simulation model:

- Required pieces: indicates how many pieces of a certain child item are necessary to produce one parent item. 

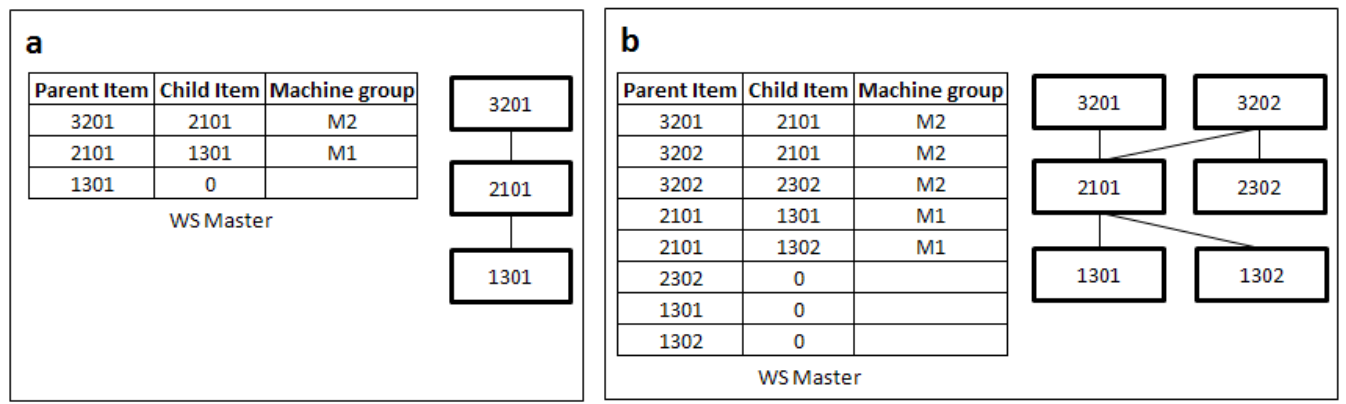

Figure 2: Routing and BOM structure

- Number of child items: indicates how many child items a parent item consist of.

- LLC: end items have a LLC of 0 and raw materials have the highest LLC

- Setup time: if a set up is necessary then the setup time describes the mean setup time

- Processing time: denotes the mean processing time to produce one parent item

- Planned lead time: indicates the value for the MRP parameter planned lead time

- Safety stock: indicates the value for the MRP parameter safety stock

- Lot size policy: indicates whether FOQ (Fixed order quantity) or FOP (Fixed order period) is applied to the MRP step lot sizing

- Parameter for lot size policy: If FOQ is chosen then this parameter denotes the quantity and if FOP is selected then this parameter refers to how many periods of the "net requirements" are combined

The WS Master allows any kind of BOM structure. If a job shop production should be studied then the machine groups refer to the single shop. Therefore information on the number of machines is required. Thus, the database provides the table of capacities where the number of machines groups and the number of identical machines for each machine group is configurable. If a flow shop production should be considered then the number of machines inside the machine group is reduced to one or more if parallel machines exist.

Moreover, customer behavior is considered by defining the amount which is ordered by the customer in the specified month, the average amount and its sigma of one customer order and the average customer required lead time and its sigma for each month and product group. Figure 3a shows the table for customer behavior whereby three product groups $(1,2,3)$ are introduced by the attribute prodgroup. Row one specifies for example that 400 pieces of product group 1 are required by the customer in month 1 . The mean of customer required lead time is 30 days and the sigma is 5 . The mean customer order size is 20 pieces and its sigma is 5. In Figure $3 \mathrm{~b}$ an example with seasonal demand for one product group is shown. Each of these attributes can be adjusted for other customer behaviors.

For verifications reasons simple structures like presented above are chosen but also more complex structures are selected. Due to the fact that the model consists of modules, it facilitates the verification of the implemented methods, because each method can be tested for its own. After verifying the single methods the whole structure is tested.

\subsection{Order Generation}

In the module order generation customer orders are generated according the table defining customer behavior. The source Customer_Order_Source illustrated in Figure 4 generates a compound Poisson demand with lognormal order amount. Therefore the rate $\lambda=\sum_{i=1}^{n} \lambda_{i}$ is adapted for each period based on the product group demand $\lambda_{i}$ per month predefined in the table customer behavior. 
Further, the single item demands for end items depend on a weight for each item whereby the following single item demand rates can be derived for each month: $\lambda_{i j}=\lambda_{i} w_{i j}$.

The split block is only necessary to ensure that the customer order is sent to the production planning module and to the customer group.
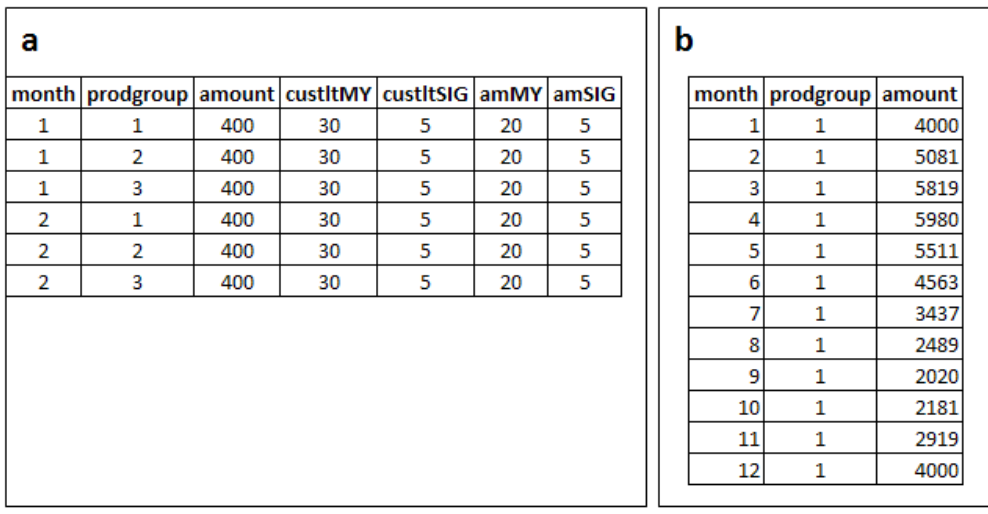

Figure 3: Customer demand

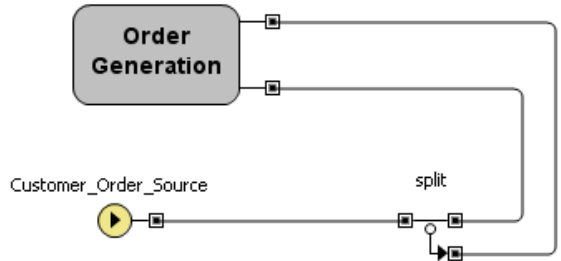

Figure 4: Order generation

\subsection{Production Planning}

Two PPC methods are implemented in this simulation model. The whole production system can either be planned by MRPII or Conwip. Figure 5 demonstrates the implementation of the production planning in the simulation model. The match block contains all orders generated by MPS or customer. Based on these orders MRPII or Conwip generate production orders. If MRPII is chosen then the production orders are created by the source Prod_Order based on MRPII algorithm explained in the following section and they are delayed in the delay block until their start date defined by the backward scheduling is reached. If Conwip is investigated then the production orders are generated by the source Prod Order Conwip. This is followed by a check on whether production orders can be released into production according to Wipcap and WAW (Work ahead window).

After releasing the production order the block select procurement decides based on the WS Master whether the order is a production order or a procurement order.

\subsubsection{MRPII}

In this stage the MRPII concept, consisting of aggregated production planning, MPS and MRP (Material Requirement Planning), is performed. The aggregated production planning solves a linear program where the target function minimizes the inventory costs and lost sales costs restricted by capacity restrictions and the inventory balancing equation. The input for the aggregated production planning is the forecast, which is the normally distributed distorted product group customer demand defined in Table 3 . The linear program is solved by an interface to FICO Xpress Solver 7 (FICO 2011). The MPS uses as input the result of the aggregated production planning and the customer orders. Two methods for calculating the MPS are implemented. For each period the forecast and the output of the production program are compared. The higher value is the MPS result. For the second method the forecast and output of the production planning are cumulated over time. These values are compared and the maximum for each period defines the output of the MPS. 


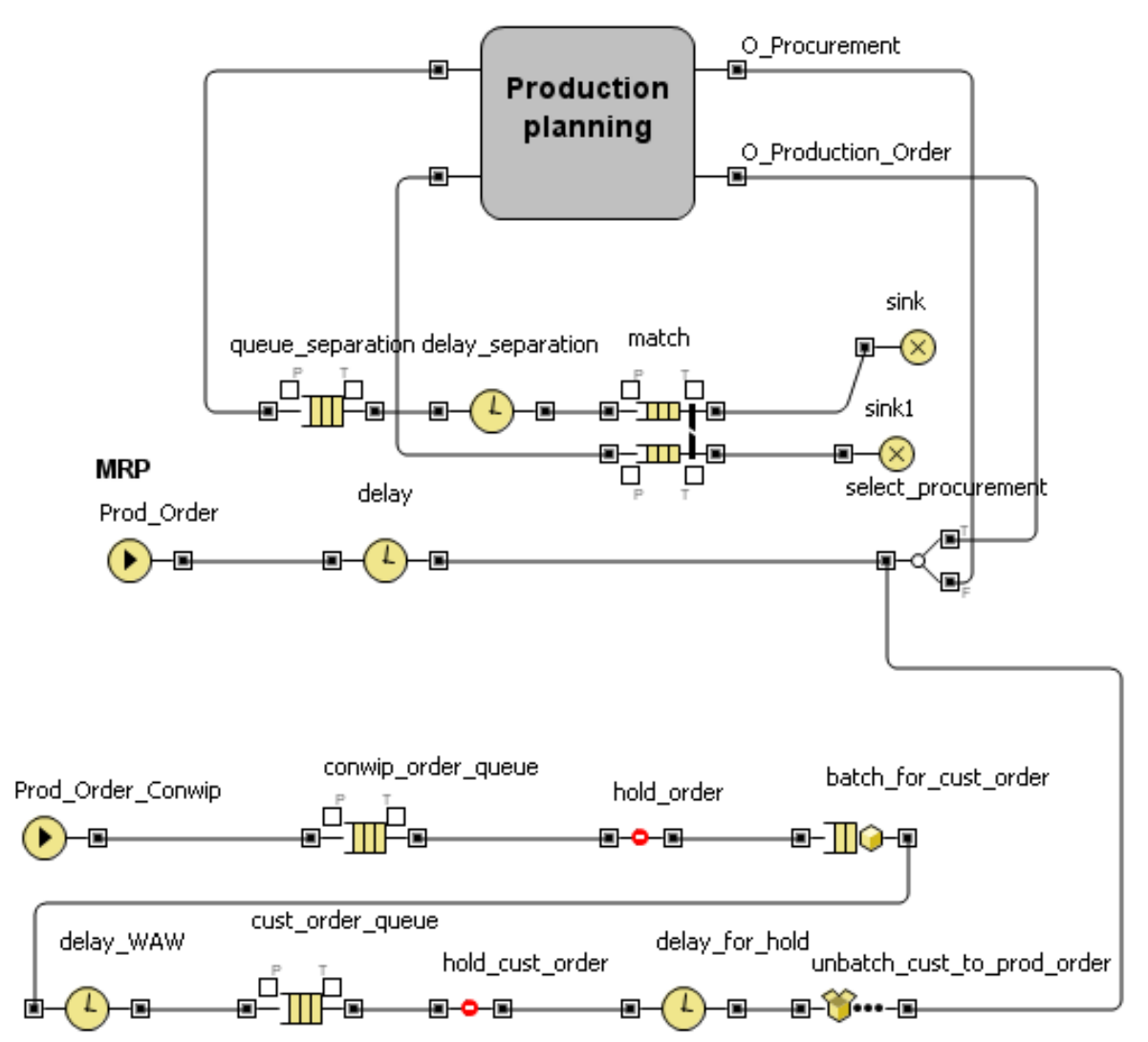

Figure 5: Production planning

For the MRP concept the inventory status file, MPS and the BOM are used as input. The MRP algorithm with its four steps netting, lot sizing, backward scheduling and BOM explosion is applied for calculating the start and end period for the planned orders including the procurement orders. The examples published in Figure 2b is extended for explaining the implemented MRP run according to Hopp and Spearman (1996). Each parent item needs one piece of its child item(s). "Gross requirements" and "scheduled receipts" are specified in Figure 6. Based on the MRP run, "projected on hand," "net requirements," "planned order receipts," and "planned order release" are calculated for all materials in the WS Master (see Figure 2b). The "adjusted scheduled receipts" introduced by Hopp and Spearman (1996) are implemented by cumulating all "scheduled receipts" and adding them to the "inventory status file."

Figure 6 shows the result of MRP run for the products 3201 and 3202. For performing the MRP procedure in the simulation model separate tables for "gross requirements," "scheduled receipts," "projected on-hand," "net requirements," "planned order receipts" and "planned order release" are created. For example the table "gross requirement" is generated if the "gross requirements" for the lowest LLC meaning product 3201 and 3202 are entered in the first two rows. After having calculated the MRP run for the lowest LLC the BOM explosion is performed. Product 2101 is needed for products 3201 and 3202 as seen in Figure 2a. Therefore the result of the planned order releases of products 3201 and 3202 are added as "gross requirements" of product 2101.

The MRP run is realized by the use of a state chart as seen in Figure 7. At the beginning of the simulation the state chart entry point "Start_PPS" is automatically selected. The following diamond indicates a query if MRP or another PPC strategy is chosen. In the case of MRP, the next step is "MRP_initialization," where the tables for the "gross requirements," "net requirements," "scheduled receipts," "projected on hand," "planned order receipts" and "planned order release" are reset, the actual "gross requirements" are counted, the MPS calculation is executed, "scheduled receipts" and "inventory 
status file" are compiled. For the "scheduled receipts" a distinction is made according to the status. All production orders where the sub material is already released, which are all orders waiting for a machine or which are already in production, are stored in a "scheduled receipts" table. All production orders which are waiting for material are stored in a separate "scheduled receipts" table. Finally, all "planned orders" are deleted because the next MRP run creates adapted planned orders.

\begin{tabular}{|c|c|c|c|c|c|c|c|c|}
\hline Product 3201 & 1 & 2 & 3 & 4 & 5 & 6 & 7 & 8 \\
\hline Gross requirements & 15 & 20 & 50 & 10 & 30 & 30 & 30 & 30 \\
\hline Scheduled receipts & 10 & 10 & & 100 & & & & \\
\hline Adjusted SRs & & 20 & 100 & & & & & \\
\hline \begin{tabular}{|l|l|} 
Projected on-hand & 20 \\
\end{tabular} & 5 & 5 & 55 & 45 & 15 & -15 & & \\
\hline Net requirements & & & & & & 15 & 30 & 30 \\
\hline Planned order receipts & & & & & & 45 & & 30 \\
\hline Planned order release & & & & 45 & & 30 & & \\
\hline
\end{tabular}

\begin{tabular}{|c|c|c|c|c|c|c|c|c|}
\hline Product 3202 & 1 & 2 & 3 & 4 & 5 & 6 & 7 & 8 \\
\hline Gross requirements & 10 & 15 & 10 & 20 & 20 & 15 & 15 & 15 \\
\hline \multicolumn{9}{|l|}{ Scheduled receipts } \\
\hline \multicolumn{9}{|l|}{ Adjusted SRs } \\
\hline \begin{tabular}{|l|l|} 
Projected on-hand & 40 \\
\end{tabular} & 30 & 15 & 5 & -15 & & & & \\
\hline Net requirements & & & & 15 & 20 & 15 & 15 & 15 \\
\hline Planned order receipts & & & & 35 & & 30 & & 15 \\
\hline Planned order release & & 35 & & 30 & & 15 & & \\
\hline
\end{tabular}

\begin{tabular}{|c|c|c|c|c|c|c|c|c|}
\hline Gross requiremnts & $\mathbf{1}$ & $\mathbf{2}$ & $\mathbf{3}$ & $\mathbf{4}$ & $\mathbf{5}$ & $\mathbf{6}$ & $\mathbf{7}$ & $\mathbf{8}$ \\
\hline Item 3201 & 10 & 15 & 10 & 20 & 20 & 15 & 15 & 15 \\
\hline Item 3202 & 10 & 15 & 10 & 20 & 20 & 15 & 15 & 15 \\
\hline Item 2101 & 0 & 35 & 0 & 75 & 0 & 45 & 0 & 0 \\
\hline \multicolumn{1}{c|}{$\ldots$} & & & & & & & & \\
\hline
\end{tabular}

\begin{tabular}{|c|c|c|c|c|c|c|c|c|}
\hline Scheduled receipts & $\mathbf{1}$ & $\mathbf{2}$ & $\mathbf{3}$ & $\mathbf{4}$ & $\mathbf{5}$ & $\mathbf{6}$ & $\mathbf{7}$ & $\mathbf{8}$ \\
\hline Item 3201 & 10 & 10 & 0 & 100 & 0 & 0 & 0 & 0 \\
\hline Item 3202 & 0 & 0 & 0 & 0 & 0 & 0 & 0 & 0 \\
\hline & & & & & & & & \\
\hline$\ldots$ & & & & & & & & \\
\hline
\end{tabular}

\begin{tabular}{|c|c|c|c|c|c|c|c|c|}
\hline Projected on-hand & $\mathbf{1}$ & $\mathbf{2}$ & $\mathbf{3}$ & $\mathbf{4}$ & $\mathbf{5}$ & $\mathbf{6}$ & $\mathbf{7}$ & $\mathbf{8}$ \\
\hline Item 3201 & 5 & 5 & 55 & 45 & 15 & -15 & 0 & 0 \\
\hline Item 3202 & 30 & 15 & 5 & -15 & 0 & 0 & 0 & 0 \\
\hline$\ldots$ & & & & & & & & \\
\hline
\end{tabular}

\begin{tabular}{|c|c|c|c|c|c|c|c|c|}
\hline Net requirements & $\mathbf{1}$ & $\mathbf{2}$ & $\mathbf{3}$ & $\mathbf{4}$ & $\mathbf{5}$ & $\mathbf{6}$ & $\mathbf{7}$ & $\mathbf{8}$ \\
\hline Item 3201 & 0 & 0 & 0 & 0 & 0 & 15 & 30 & 30 \\
\hline Item 3202 & 0 & 0 & 0 & 15 & 20 & 15 & 15 & 15 \\
\hline$\ldots$ & & & & & & & & \\
\hline
\end{tabular}

\begin{tabular}{|c|c|c|c|c|c|c|c|c|}
\hline Planned order receipts & $\mathbf{1}$ & $\mathbf{2}$ & $\mathbf{3}$ & $\mathbf{4}$ & $\mathbf{5}$ & $\mathbf{6}$ & $\mathbf{7}$ & $\mathbf{8}$ \\
\hline Item 3201 & 0 & 0 & 0 & 0 & 0 & 45 & 0 & 30 \\
\hline Item 3202 & 0 & 0 & 0 & 35 & 0 & 30 & 0 & 15 \\
\hline$\ldots$ & & & & & & & & \\
\hline
\end{tabular}

\begin{tabular}{|c|c|c|c|c|c|c|c|c|}
\hline Planned order release & $\mathbf{1}$ & $\mathbf{2}$ & $\mathbf{3}$ & $\mathbf{4}$ & $\mathbf{5}$ & $\mathbf{6}$ & $\mathbf{7}$ & $\mathbf{8}$ \\
\hline Item 3201 & 0 & 0 & 0 & 45 & 0 & 30 & 0 & 0 \\
\hline Item 3202 & 0 & 35 & 0 & 30 & 0 & 15 & 0 & 0 \\
\hline$\ldots$ & & & & & & & & \\
\hline
\end{tabular}

Figure 6: MRPII procedure according to Hopp and Spearman (1996)

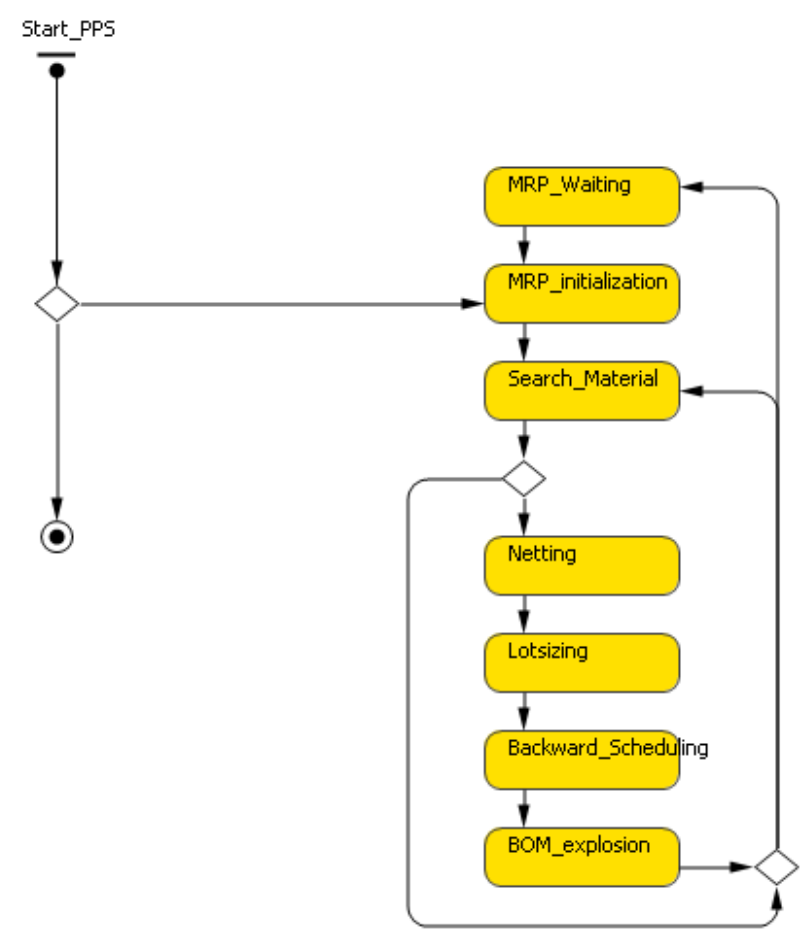

Figure 7: State chart 
The MPS calculation is not performed for each MRP run. Moreover, the MPS is valid for a customized number of MRP runs. After this number is reached a new MPS is calculated.

The next step of the state chart "Search_Material" is searching for a material, which has the same LLC as the material before. In the beginning the first entry with the lowest LLC in the table WS Master is selected. After the calculation of the four MRP steps for this material the next material with the same low level code is selected. If no further material for the actual LLC exits, then the LLC is increased and the procedure for searching for a material starts again. If the MRP run for the last material of the highest LLC is finished, then the state MRP_Waiting for the state chart is reached. The system is in this state as long as a Boolean is set true by an event with a recurrence time of the MRP period.

\subsubsection{Conwip}

If Conwip is chosen as PPC, the customer orders are released into production according to Spearman, Woodruff, and Hopp (1990). Therefore, the MPS is deactivated and only customer orders are considered. The source Prod_Order_Conwip generates all production orders which are necessary to produce the final product entering the match block in Figure 5. All these orders are batched together in the block batch_for_cust_order.

In the delay block delay_WAW the Orders are delayed until the customer required due date is within the WAW. Finally the check of the Wipcap is performed. If the order plus the actual WIP is smaller than the Wipcap then the order can pass the hold block hold_cust_order otherwise the order has to wait until the Wipcap is not violated. The orders in the queue cust_order_queue are sorted based on their due dates according to Spearman, Woodruff, and Hopp (1990). A second possibility for checking the Wipcap is implemented, which considers the FGI. That means WIP plus FGI have to be smaller than or equal to the Wipcap.

After having passed the Wipcap request (hold_cust_order) the batched orders are unbatched so that the procurement orders can activate the purchase process of raw and purchased parts. Moreover, production can release material to produce the required products.

\subsection{Procurement}

The procurement module orders raw material and purchased articles according to the procurement orders generated by the production planning module. An exponential replenishment lead time distribution is implemented in the procurement process, whereby the delay block in Figure 8 is responsible for the distribution. The mean replenishment lead time is defined in the WS Master. It is crucial that the inputs for the procurement are orders. The ordered items, however, are the output. This transfer is solved by the use of the source Raw_material which injects material entities. The source is triggered after the procurement order has been delayed by the replenishment lead time and receives the match block. After all material entities are created the procurement order is deleted in the sink.

\subsection{Production Control}

The production control module receives production orders at port I_Prod_Order, which are released by the production planning module and produced items at port I_Product, which are stored in the sub module Storage (see Figure 9). Basically the sub module Storage is a replicated array list where the material is stored. According to the production orders, which are waiting in the match block, the necessary material is taken from inventory if it is available. The production order and its material are then sent to the next machine group defined by the attribute Machine Group from the table WS Master. 


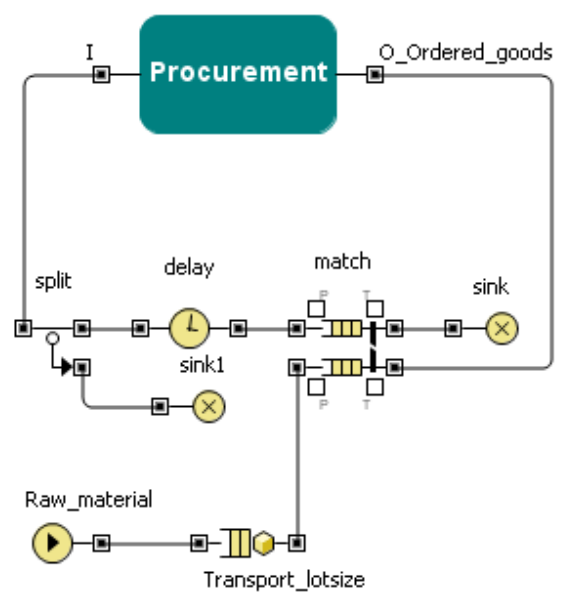

Figure 8: Procurement

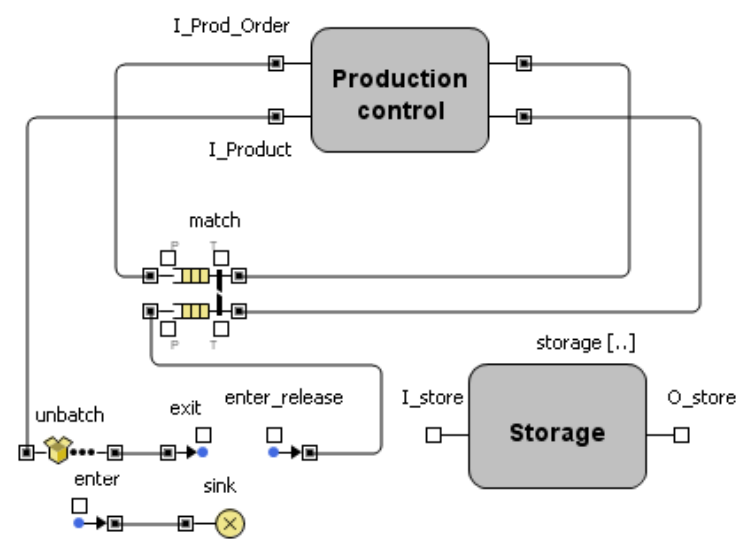

Figure 9: Production Control

\subsection{Machine Group}

Each machine group consists of one or more machines which are substitutes for each other to produce a material according the WS Master. Based on the table capacities the machine groups and machines are initialized. The machine group is shown in Figure 10. Material arrives at the port enter_Prod and the production order at port enter_order. The production order is waiting in the match block until each material of the production lot size is finished. The sub module machine is replicated based on the table capacities.

Exponentially distributed processing and setup times are implemented in the machine module. Moreover, failures are also included based on exponentially distributed values for MTBF and MTTR. MTBF and MTTR are predefined in the table capacities for each machine.

The dispatching rules are implemented in the queue in Figure 10. FIFO, EDD, shortest processing time (SPT) and longest processing time (LPT) are included.

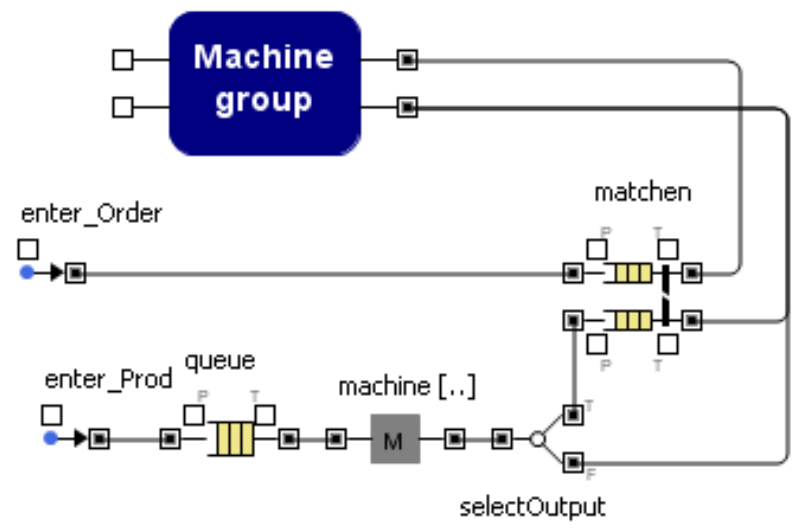

Figure 10: Machine group

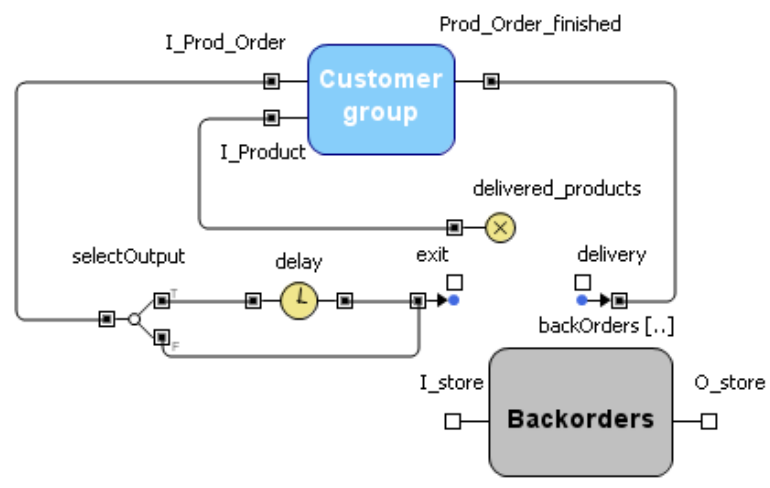

Figure 11: Customer group

\subsection{Customer Group}

The customer orders enter the customer group at port I_Prod_order and are delayed until their due date is reached as demonstrated in Figure 11. If an end item is available in inventory then it is released in response to the customer order. If the product is not available, then the order is stored in the sub module Backorders. Every time an end item is released into the FGI a check as to whether backorders can be sat- 
isfied is carried out. After the delivery process of the customer required end items is finished the customer order is send back to the production planning module. In the match block illustrated in Figure 5 the order which was responsible for releasing the production orders is dispatched and deleted, because the customer orders has been satisfied.

\subsection{Analysis}

The logistics performance of the production system is monitored by measuring service level, average tardiness, average lateness of production orders, average raw material inventory, average WIP (work in progress), average FGI, average production lead time, average FGI lead time, average utilization of the machine groups and average throughput. This data is written in the table in the database to facilitate dealing with experiment or optimization runs.

Service level is calculated at the end of the simulation time by dividing all customer orders which were on time by all delivered customer orders. Tardiness measures the difference between delivery and due date, if an order is late. Hence, lateness includes both customer orders being too late and customer orders being too early compared to the due date. Due to the fact that in the module customer group the customer orders are delayed until the required due date is reached the metrics lateness is only used for production orders and not for customer orders. Both lateness and tardiness are important performance indicators for the whole production system. Therefore the average lateness and tardiness are investigated.

For calculating average WIP, finished goods and raw materials are not included. Therefore own metrics for average raw material inventory and average finished goods (FGI) are introduced.

Average production lead time indicates the duration between the time the production orders are released from production planning module to the production control module and the time the production orders are finished at the machine group module. Average FGI lead time measures the difference between delivery and due date if an order is on time.

Also the average utilization for each machine group is measured and the throughput of finished goods for the whole simulation time is calculated by summing up all delivered products at the end of the simulation.

\section{CONCLUSION}

The paper introduces a flexible discrete event simulation model for analyzing production systems. The model is based on different modules which are not connected directly together. Moreover, the material flow is based on the information set in database for routing and BOM. This allows the analysis of the logistical performance of any structure applied in BOM and routing. Stochastic behavior for customer performance, processing times, set up times and purchasing lead time are included.

The model combines three hierarchical levels whereby their interaction can be tested. On the highest level, the long term view, where the MPS calculates the aggregated production program can be monitored for different customer behavior. For the midterm view, two PPC methods MRPII and Conwip are implemented. Finally different dispatching rules can be compared for the short term view.

Further research can be conducted to set up an interface which downloads the data from an Enterprise Resource Planning system, aggregates the information and stores the information in a database. Based on this database the simulation model is initialized and the production system can be analyzed.

\section{ACKNOWLEDGMENTS}

This paper was written within the framework of the project "Robust Strategies for hierarchical production planning" (project number L534-N13) funded by the Austrian Science Fund (FWF). 


\section{REFERENCES}

Abdul-Kader, W., and A. Gharbi. 2002. "Capacity Estimation of a Multi-Product Unreliable Production Line." International Journal of Production Research 40: 4815-4834.

Anglani, A., A. Grieco, M. Pacella, and T. Tolio. 2002. "Object-Oriented Modeling and Simulation of Flexible Manufacturing Systems: A Rule-Based Procedure." Simulation Modelling Practice and Theory 10: 209-234.

Borenstein, D. 2000. "Implementation of an Object-Oriented Tool for the Simulation of Manufacturing Systems and its Application to Study the Effects of Flexibility." International Journal of Production Research 38: 2125-2142.

Delen, D., P. C. Benjamin, and M. Erraguntla. 1998. "Integrated Modeling and Analysis Generator Environment (IMAGE): a Decision Support Tool." In Proceedings of the 1998 Winter Simulation Conference, Edited by D. J. Medeiros, E. F. Watson, J. S. Carson, M. S. Manivannan, 1401-1408. Piscataway, New Jersey: Institute of Electrical and Electronics Engineers, Inc.

Fawcett, S. E., and M. B. Cooper. 1998. "Logistics Performance Measurement and Customer Success." Industrial Marketing Management 27: 341-357.

FICO 2011. "FICO ${ }^{\text {TM }}$ Xpress Optimization Suite." Accessed September 22, 2011. www.fico.com/en/Products/DMTools/Pages/FICO-Xpress-Optimization-Suite.aspx.

Hax, A.C., and H.C. Meal. 1975. "Hierarchical Integration of Production Planning and Scheduling." In Studies in The Management Science, edited by Martin K. Starr, 53-69. New York: North Holland American Elsevier.

Heim, J. A. 1997. "Integrating Distributed Simulation Objects." In Proceedings of the 1997 conference on Winter simulation, edited by S. Andradóttir, K. J. Healy, D. H. Withers, B. L. Nelson, 532-538. Piscataway, New Jersey: Institute of Electrical and Electronics Engineers, Inc.

Hopp, W. J., and M. L. Spearman. 1996. Factory Physics: Foundations of Manufacturing Management. Chicago: Irwin.

Huang, M., D. Wang, and W. H. Ip. 1998. "Simulation Study of CONWIP for a Cold Rolling Plant.” International Journal of Production Economics 54: 257-266.

Jodlbauer, H., and A. Huber. 2008. "Service-level Performance of MRP, Kanban, CONWIP and DBR due to Parameter Stability and Environmental Robustness." International Journal of Production Research 46: 2179-2195.

Jodlbauer, H., and K. Altendorfer. 2010. "Trade-off Between Capacity Invested and Inventory Needed." European Journal of Operational Research 203: 118-133.

Koh, S.-G, and R. L. Bulfin. 2004. "Comparison of DBR with CONWIP in an Unbalanced Production Line with Three Stations." International Journal of Production Research 42: 391-404.

Kutanoglu, E., and I. Sabuncuoglu. 1999. "An Analysis of Heuristics in a Dynamic Job Shop with Weighted Tardiness Objectives." International Journal of Production Research 37: 165-187.

Meal, H. C. 1984. "Putting Production Decisions Where They Belong." Harvard Business Review 62: 102-111.

Perera, T., and K. Liyanage. 2000. "Methodology for Rapid Identification and Collection of Input Data in the Simulation of Manufacturing Systems." Simulation Practice and Theory 7: 645-656.

Randell, L.G., and G.S. Bolmsjo. 2001. "Database Driven Factory Simulation: A Proof-Of-Concept Demonstrator." In Proceedings of the 2001 Winter Simulation Conference, edited by B. A. Peters, J. S. Smith, D. J. Medeiros, M. W. Rohrer, 977-983. Piscataway, New Jersey: Institute of Electrical and Electronics Engineers, Inc.

Spearman, M. L., D. L. Woodruff, and W. J. Hopp. 1990. "CONWIP: A Pull Alternative to Kanban." International Journal of Production Research 28: 879-894.

Srinivasan, K., and S. Jayaraman. 1997. "Integration of Simulation with Enterprise Models." In Proceedings of the 1997 conference on Winter simulation, edited by S. Andradóttir, K. J. Healy, D. H. With- 
ers, B. L. Nelson, 1352-1356. Piscataway, New Jersey: Institute of Electrical and Electronics Engineers, Inc.

Thompson, M. B. 1994. "Expanding Simulation Beyond Planning and Design.” Industrial Engineering 26: 64 .

Trybula, W. J. 1994. "Building Simulation Models Without Data." In Proceedings of the IEEE International Conference of Systems, Man and Cybernetics 1994, 209-214. San Antonio: Institute of Electrical and Electronics Engineers, Inc.

Whitman, L., B. Huff, and A. Presley. 1997. "Structured Models and Dynamic Systems Analysis: The Integration of the IDEF0/IDEF3 Modeling Methods and Discrete Event Simulation." In Proceedings of the 1997 conference on Winter simulation, edited by S. Andradóttir, K. J. Healy, D. H. Withers, B. L. Nelson, 518-524. Piscataway, New Jersey: Institute of Electrical and Electronics Engineers, Inc.

\section{AUTHOR BIOGRAPHIES}

ALEXANDER HÜBL works as a Research Associate in the field of Operations Management at the University of Applied Sciences, Steyr (Austria). His research interests are discrete event simulation and quantitative methods for capacity setting. His email address is alexander.huebl@fh-steyr.at.

KLAUS ALTENDORFER works as an Assistant Professor in the field of Operations Management at the University of Applied Sciences, Steyr (Austria). His e-mail address is klaus.altendorfer@fh-steyr.at.

HERBERT JODLBAUER is the Director of Studies of the degree course "Production and Management" and "Operations Management" at the University of Applied Sciences, Steyr (Austria). He received his $\mathrm{PhD}$ degree in engineering with distinction and has professional experience in process optimization and production planning and control. His e-mail address is herbert.jodlbauer@fh-steyr.at.

MARGARETHA GANSTERER works as a Research Assistant at the Department of Business Administration of the University of Vienna. She is interested in quantitative methods in the context of supply chain management and production optimization. She recently finished her $\mathrm{PhD}$ studies on a combination of simulation and optimization applied to different sized supply chain networks. Her e-mail address is margaretha.gansterer@univie.ac.at.

RICHARD F. HARTL is a full Professor at the Department of Business Administration (Production and Operations Management) of the University of Vienna. Since 2007 he has held the position of an extramural fellow at CentER (University of Tilburg). His research interests are in quantitative methods in production and operations management, and quantitative methods in transportation, and optimal control. His email address is richard.hartl@univie.ac.at. 